\title{
BMJ Open Relationship between food insecurity and smoking status among women living with and at risk for HIV in the USA: a cohort study
}

Lila A Sheira (D) , ${ }^{1}$ Edward A Frongillo, ${ }^{2}$ Judith Hahn, ${ }^{1}$ Kartika Palar, ${ }^{1}$ Elise D Riley, ${ }^{1}$ Tracey E Wilson, ${ }^{3}$ Adebola Adedimeji, ${ }^{4}$ Daniel Merenstein, ${ }^{5}$ Mardge Cohen, ${ }^{6}$ Eryka L Wentz, ${ }^{7}$ Adaora A Adimora, ${ }^{8,9}$ Ighovwerha Ofotokun, ${ }^{10}$ Lisa Metsch, ${ }^{11}$ Janet M Turan, ${ }^{12}$ Phyllis C Tien, ${ }^{13,14}$ Sheri D Weiser (D) ${ }^{1,15}$

To cite: Sheira LA, Frongillo EA, Hahn J, et al. Relationship between food insecurity and smoking status among women living with and at risk for HIV in the USA: a cohort study. BMJ Open 2021;11:e054903. doi:10.1136/ bmjopen-2021-054903

- Prepublication history for this paper is available online. To view these files, please visit the journal online (http://dx.doi. org/10.1136/bmjopen-2021054903).

Received 30 June 2021 Accepted 10 August 2021
Check for updates

(C) Author(s) (or their employer(s)) 2021. Re-use permitted under CC BY-NC. No commercial re-use. See rights and permissions. Published by BMJ.

For numbered affiliations see end of article.

Correspondence to

Lila A Sheira;

lila.sheira@ucsf.edu

\section{ABSTRACT}

Objectives People living with HIV (PLHIV) in the USA, particularly women, have a higher prevalence of food insecurity than the general population. Cigarette smoking among PLHIV is common (42\%), and PLHIV are 6-13 times more likely to die from lung cancer than AIDSrelated causes. This study sought to investigate the associations between food security status and smoking status and severity among a cohort of predominantly low-income women of colour living with and without HIV in the USA.

Design Women enrolled in an ongoing longitudinal cohort study from 2013 to 2015.

Setting Nine participating sites across the USA. Participants 2553 participants enrolled in the Food Insecurity Sub-Study of the Women's Interagency HIV Study, a multisite cohort study of US women living with HIV and demographically similar HIV-seronegative women.

Outcomes Current cigarette smoking status and intensity were self-reported. We used cross-sectional and longitudinal logistic and Tobit regressions to assess associations of food security status and changes in food security status with smoking status and intensity. Results The median age was 48. Most respondents were African-American/black (72\%) and living with HIV (71\%). Over half had annual incomes $\leq$ US $\$ 12000$ $(52 \%)$. Food insecurity (44\%) and cigarette smoking (42\%) were prevalent. In analyses adjusting for common sociodemographic characteristics, all categories of food insecurity were associated with greater odds of current smoking compared with food-secure women. Changes in food insecurity were also associated with increased odds of smoking. Any food insecurity was associated with higher smoking intensity.

Conclusions Food insecurity over time was associated with smoking in this cohort of predominantly low-income women of colour living with or at risk of HIV. Integrating alleviation of food insecurity into smoking cessation programmes may be an effective method to reduce the smoking prevalence and disproportionate lung cancer mortality rate particularly among PLHIV.
Strengths and limitations of this study

- Although much of the previous literature about smoking among people living with HIV has been conducted among white men, this study was conducted among a large study sample of women and predominantly women of colour.

- The analyses allowed the study to estimate multiple relational structures between food insecurity and smoking, including smoking status and smoking intensity.

- The study lacked information on participant use of other tobacco products, notably e-cigarettes, precluding a more comprehensive definition of tobacco use as an outcome.

- Smoking status varied little over time, which may have limited estimation of the relationship between changes in smoking status and in food security.

\section{BACKGROUND}

Cigarette smoking is among the leading causes of excess mortality worldwide ${ }^{12}$ and the leading risk factor for preventable death in high-income countries such as the USA. ${ }^{3}$ The prevalence of smoking in the US general adult population was $14 \%$ in $2017 .^{4}$ In 2019 , the prevalence of smoking among men was $15.3 \%$ compared with $12.7 \%$ of women. ${ }^{5}$ The prevalence of cigarette smoking is also substantially higher among low-income individuals at and below the federal poverty level, among whom $41 \%$ of men and $33 \%$ of women smoke $^{6}$ and higher proportions use all other forms of tobacco, including e-cigarettes. ${ }^{7}$ Women in general have a harder time quitting smoking, ${ }^{8}$ both "cold-turkey' ${ }^{9}$ and through other methods such as the patch, ${ }^{10}$ compared with men, leading to longer lifetime smoking duration and nicotine exposure. 
The prevalence of smoking among people living with HIV (PLHIV) is 42\%, similar to that among the low-income general population and more than double the general population estimates. ${ }^{11}$ Beyond the welldocumented sequelae of cigarette smoking in the general population, ${ }^{3}$ PLHIV who are smokers additionally experience a higher risk of pneumonia, ${ }^{12}$ emphysema ${ }^{13}$ and other illnesses of the lung, ${ }^{14}$ compared with their HIVseronegative counterparts who smoke. Further, PLHIV who smoke also have higher odds of a detectable viral load $^{1516}$ and faster progression to AIDS compared with non-smoking PLHIV. ${ }^{17}$ Nearly one-quarter of deaths among PLHIV can be attributed to current smoking, ${ }^{18}$ and PLHIV who smoke are also 6-13 times more likely to die from lung cancer than from AIDS-related causes. ${ }^{19}$

Despite sex differences in cigarette smoking prevalence in the general US population, ${ }^{4}$ cigarette smoking prevalence does not differ by sex among PLHIV. Smoking among women living with HIV (WLWH) may have additional reproductive and maternal health consequences, including a higher risk of pre-eclampsia than both HIV seronegative- and non-smoking WLWH counterparts, ${ }^{20}$ increased fetal morbidity compared with HIV seronegative smokers ${ }^{21}$ and earlier onset of natural menopause compared with non-smoking WLWH. ${ }^{22}$ On the whole, these smoking-specific health consequences may have additive or multiplicative interactions with general HIVrelated conditions, ${ }^{23}$ thereby reducing the immunological support of antiretroviral therapy (ART).$^{24}$

Food insecurity, defined as 'the uncertain or limited availability of nutritionally adequate or safe food or the inability to procure food in socially acceptable ways, ${ }^{25} 26$ is prevalent in low-income households and has been linked to smoking in the general population. ${ }^{27}{ }^{28}$ Food insecurity affects $12 \%$ of American households and $16 \%$ of households with a child under $18 .^{29}$ Food insecurity is more prevalent among households led by women and women living alone, ethnic and racial minorities, and households with children (compared with the general US prevalence) ${ }^{29}$

Estimates of food insecurity among PLHIV range from $20 \%$ to $50 \%,{ }^{30} 31$ with higher prevalence among WLWH compared with their male counterparts. ${ }^{32} 33$ Food insecurity among PLHIV is associated with decreased mental and physical health status, ${ }^{34}$ suboptimal adherence to ART, ${ }^{35}$ use of illicit substances, ${ }^{36}$ and increased HIVrelated morbidity and HIV mortality. ${ }^{37}$ Important limitations of the studies investigating smoking among PLHIV include that they were conducted among predominantly male populations living with HIV ${ }^{38-40}$ lacked granularity in the smoking variable ${ }^{3840}$ or did not examine smoking severity. ${ }^{39}$ Given that tobacco use is the most important preventable cause of excess mortality worldwide, ${ }^{12}$ with increased health consequences to PLHIV and WLWH specifically, expanding our understanding of the role of food insecurity as a potentially modifiable factor among WLWH is vital to reducing these health disparities. Therefore, we conducted an analysis of data from the Women's
Interagency HIV Study (WIHS) to understand the associations between food insecurity and smoking over time. We hypothesised that: (1) greater severity of current food insecurity would be associated with higher odds of being a current smoker, (2) change in food security status over time would be associated with change in smoking status and (3) greater severity of current food insecurity would be associated with higher intensity of smoking.

\section{METHODS \\ Data}

Data for this study originated from the WIHS, a longitudinal cohort study of WLWH and demographically similar HIV-seronegative controls in the USA that began in 1993 and enrolled women over four recruitment waves in 1994-1995, 2001-2002, 2011-2012 and 2013-2015. The recruitment wave of 2001-2002 prioritised the recruit of younger participants, and in those with HIV, participants who were ART-naive, while the 2011-2012 wave was to replace participants who had died in the interim. From 2013-2015, four new sites in the Southern USA were added to enrol women representative of the distribution of the HIV epidemic in the USA. ${ }^{41-43}$ Recruitment methods are described in detail elsewhere $;^{42}$ in brief, women were recruited from HIV care clinics, churches, HIV community organisations and social service agencies. For the duration of this study, the WIHS collected sociobehavioural, biological and clinical data from all participants during semiannual visits using intervieweradministrated standardised instruments, physical examinations and standard phlebotomy. The physical examination includes standard anthropometry, weight and a gynaecological examination. Immunological and virological biomarker measurements included current CD4 count and HIV RNA viral load.

Beginning in 2013, the Food Insecurity Substudy added data on comprehensive measures of food security, dietary intake, household savings and food support among all WIHS women at nine sites: Bronx, New York; Brooklyn, New York; Washington, DC; Chicago, Illinois; San Francisco, California; Chapel Hill, North Carolina; Miami, Florida; Birmingham, AL/Jackson, Mississippi and Atlanta, Georgia. During the substudy period, there were 12464 person-visits in total in the WIHS among 2613 unique women. Of these person-visits, 608 were abbreviated visits during which women only contributed laboratory specimens. During the substudy period, 317 women were deactivated or disenrolled from the WIHS, mainly due to death $(110,34.4 \%)$ or unenrolment due to a site losing funding (Brooklyn only; 114, 36.6\%). The rest were due to participant's decision $(10 \%)$, site's decision $(3.4 \%)$ or travel reasons $(16.7 \%)$. The analyses in this paper used data on 11692 person-visits from 2553 unique women in total (1803 living with and 750 without HIV collected from April 2013 to March 2016 at every semiannual visit). Of these women, 1689 had been recruited prior to the newest recruitment wave and could therefore 
contribute up to six visits in total during the substudy period; the median number of visits attended was 6 (IQR: 5-6). The remaining 864 women were recruited or transferred to the Southern sites during the latest recruitment wave occurring contemporaneously with our substudy. These women could contribute between two and five visits; the median number of visits attended was 4 (IQR: 3-4). Participants provided written informed consent and were compensated for participation.

\section{Measures}

The exposure was food insecurity, measured using the US Department of Agriculture's Household Food Security Module (HFSSM).$^{44}$ The HFSSM has been validated in high-resource settings among both vulnerable populations ${ }^{45} 46$ and those living with HIV, and is the reference measure of food security in the USA. ${ }^{47}$ The HFSSM includes 18 items about insufficient food quantity, low diet quality, uncertainty about food and food affordability. ${ }^{45}$ The HFSSM uses recall periods of 12 months and 30 days; the WIHS module was worded to ask about food security over the previous six months or since the last WIHS visit. The HFSSM scoring algorithm categorises individuals as having high, marginal, low or very low food security. ${ }^{47}$ The HFSSM was available for $98.6 \%$ of respondents who were offered the food insecurity substudy (ie, did not have abbreviated visits), thus, no missing data methods were used for the exposure variable. Cronbach's alpha for the HFSSM in this sample was 0.91, indicating high internal consistency.

The primary outcomes were (1) current cigarette smoking status (smoker vs non-smoker) and (2) smoking intensity (number of cigarettes/day). Both outcomes were assessed by self-report at each visit during the interviewer-administered interview. Participants were asked 'Since your study visit on [previous study visit date], have you smoked cigarettes?' Those who responded yes were further prompted to recall how many cigarettes on average they smoked per day. Given the non-normal distribution of cigarettes smoked per day, the values above zero for this variable were transformed by the natural logarithm. Those who reported zero cigarettes per day were not transformed and were retained as being left-censored. Complete smoking data were available for $99.5 \%$ of respondents of the food insecurity substudy module, thus, no missing data methods were used for the outcome. Per WIHS protocol, all participants who reported current smoking were subsequently referred to a smoking cessation programme.

Covariates: Covariates were selected a priori based on review of the literature regarding food security and smoking. Covariates were HIV status (seropositive or seronegative (reference group)), age at visit (per year), race/ ethnicity (non-Hispanic white (reference group), nonHispanic African-American/black, Hispanic and nonHispanic other), annual household income as collected by WIHS ( $\leq$ US $\$ 12000$ (reference group), US $\$ 12001-$ US $\$ 24000$, US $\$ 24$ 001-US\$36 000, US\$36 001-US\$75000 and $\geq$ US $\$ 75$ 001), employment status (employed (reference group) or unemployed), marital status (partnered (reference group), divorced/widowed/separated, never married or other), educational attainment (less than high school education (reference group) or greater than a high school education or equivalent), and if they had child dependents under age 18 in the household (none (reference group) or yes). Response options were in reference to the previous 6 months. Covariate data were missing from 373 unique person-visits (3.2\% of personvisits), thus, no missing data methods were used.

Given that food insecurity is associated with several mental health outcomes including depression, ${ }^{34}$ anxiety and stress, ${ }^{48}$ and illicit substance use, ${ }^{36}$ and there is likely a bidirectional association between smoking and mental health, ${ }^{49}$ mental health may be a mediator rather than a confounder on the path from food insecurity to smoking outcomes. Therefore, we did not adjust for mental health variables, as these could potentially be on the causal path from food insecurity to smoking outcomes.

\section{Analysis}

Summary statistics were obtained for food insecurity, the smoking outcomes and all covariates at study baseline (ie, the first visit during the Food Insecurity Sub-Study). We used a logistic regression model with one cross-sectional sample at the first measure of food insecurity (food insecurity substudy baseline) to assess the association between food security status and the odds of being a current smoker (hypothesis 1). We also modelled an interaction term between food security and HIV status to assess whether food security in the presence of HIV-seropositivity was associated with differential odds of smoking compared with food secure, HIV-seronegative women. Next, we used a longitudinal logistic regression model with fixed effects for individuals to assess the association between changes in food security status and the odds of becoming a current smoker compared with becoming a nonsmoker (hypothesis 2). This model ruled out potential confounding by unobserved or observed time-invariant characteristics. The fixed-effects model removed all individuals who did not have a change in smoking status over the study visits, allowing us to examine just those who had a change in smoking status and leaving a sample of 344women (comprising 1700 person-visits). Given that this model removes person-to-person variability, it allows for the interpretation of change as effects are generated only by those who experience any change. The coefficients from this model are interpreted as adjusted ORs (AORs). Finally, we used longitudinal Tobit regression to model the association between food security and smoking intensity (natural logarithm of cigarettes/day) (hypothesis 3). Tobit models allow for censoring and were thus implemented given that a large proportion of the values for cigarettes per day were left-censored as over half of women in the sample were non-smokers. Given that cigarettes per day was transformed to the logarithmic scale, the results from the Tobit model are presented as 
Table 1 Sociodemographic characteristics of the sample at first visit in the food insecurity substudy, women's Interagency HIV Study ( $\mathrm{n}=2553$ unique women)

\begin{tabular}{|c|c|c|c|}
\hline & All women & HIV-seropositive $\mathrm{N}=1803$ & HIV-seronegative $\mathrm{N}=750$ \\
\hline \multicolumn{4}{|l|}{ N (\%) or median (IQR) } \\
\hline \multicolumn{4}{|l|}{ Current food security (FS) } \\
\hline High FS & 1419 (55.6\%) & $1006(55.8 \%)$ & $413(55.1 \%)$ \\
\hline Marginal FS & 405 (15.9\%) & $287(15.9 \%)$ & $118(15.7 \%)$ \\
\hline Low FS & $372(14.6 \%)$ & $263(14.6 \%)$ & $109(14.5 \%)$ \\
\hline Very low FS & $357(14.0 \%)$ & $247(13.7 \%)$ & $110(14.7 \%)$ \\
\hline Current smoker & $1075(42.1 \%)$ & $706(39.2 \%)$ & $369(49.2 \%)$ \\
\hline Age at visit, year (median, IQR) & $47.7(40.4-53.8)$ & $48.2(41.3-54.0)$ & $46.1(38.1-53.0)$ \\
\hline \multicolumn{4}{|l|}{ Race } \\
\hline Non-Hispanic white & $255(10.0 \%)$ & $196(10.9 \%)$ & $59(7.9 \%)$ \\
\hline Hispanic & $377(14.8 \%)$ & $262(14.5 \%)$ & $115(15.3 \%)$ \\
\hline Non-Hispanic African American/black & $1829(71.6 \%)$ & $1290(71.5 \%)$ & $539(71.9 \%)$ \\
\hline Non-Hispanic other & $92(3.6 \%)$ & $55(3.1 \%)$ & $37(4.9 \%)$ \\
\hline \multicolumn{4}{|l|}{ Annual household income (US\$) } \\
\hline$<$ US\$12000 & $1261(51.9 \%)$ & $925(53.7 \%)$ & $337(47.5 \%)$ \\
\hline US\$12001-US\$24000 & $541(22.3 \%)$ & $381(22.1 \%)$ & $160(22.5 \%)$ \\
\hline US\$24 001-US\$36000 & $267(11.0 \%)$ & $180(10.5 \%)$ & $87(12.3 \%)$ \\
\hline US\$36001-US\$75000 & $249(10.2 \%)$ & $153(8.9 \%)$ & $96(13.5 \%)$ \\
\hline US\$75001 & $113(4.7 \%)$ & $83(4.8 \%)$ & $30(4.2 \%)$ \\
\hline Employed (ref: unemployed) & $891(35.0 \%)$ & $592(32.9 \%)$ & $299(40.0 \%)$ \\
\hline \multicolumn{4}{|l|}{ Marital status } \\
\hline Partnered & $762(30.8 \%)$ & $531(30.4 \%)$ & $231(32.0 \%)$ \\
\hline Divorced/separated/widowed & $660(26.7 \%)$ & $476(27.2 \%)$ & $184(25.4 \%)$ \\
\hline Never married & 800 (32.4\%) & 577 (33.0\%) & $223(30.8 \%)$ \\
\hline Other & $250(10.1 \%)$ & $165(9.4 \%)$ & $85(11.8 \%)$ \\
\hline \multicolumn{4}{|l|}{ Education (ref: <high school) } \\
\hline zHigh school education & $1719(67.4 \%)$ & $1204(66.8 \%)$ & $515(68.8 \%)$ \\
\hline \multicolumn{4}{|l|}{ Child dependents (ref: no) } \\
\hline Yes & $986(38.6 \%)$ & $664(36.8 \%)$ & $322(42.9 \%)$ \\
\hline
\end{tabular}

exponentiated coefficients and interpreted as a relative difference (ie, multiplicative factor) compared with the reference category. All analyses were conducted using Stata V.15 (StataCorp).

\section{Patient and public involvement}

There was no patient or public involvement in the development of the research questions or in the analyses.

\section{RESULTS}

At the Food Insecurity Sub-Study baseline, $42 \%$ of women reported being current smokers and $44 \%$ reported any category of food insecurity (table 1). Among current smokers, the median number of cigarettes smoked per day was 5 (IQR: 3-10). The median age of women was 48 years (IQR: $40-54)$ and women were predominantly HIVseropositive (71\%) and of African-American/black race
(72\%), followed by Hispanic women (15\%). Nearly twothirds of the women reported an education equivalent to or greater than high school $(67.4 \%)$ and were unemployed at baseline $(65 \%)$. Over half had annual household incomes less than US\$12000.

In the unadjusted model which included 2228 women, marginal, low and very low food security was associated with 1.64 (95\% CI: 1.26 to 2.14), 1.90 (95\% CI: 1.46 to 2.48) and 2.44 (95\% CI: 1.84 to 3.23) times greater odds of being a current smoker (table 2). In the adjusted model among 2133women, current marginal, low and very low food security was associated with 1.52 (95\% CI: 1.14 to 2.04 ), 1.70 (95\% CI 1.28 to 2.27 ) and 1.91 (95\% CI 1.42 to 2.59) times greater odds of being a current smoker compared with those with high food security (all $\mathrm{p}<0.01$; table 3 ). HIV-seropositivity was associated with lower odds of being a current smoker (AOR: 0.66; 95\% CI 
Table 2 Unadjusted associations between food security (FS) and smoking outcomes

\section{Cross-sectional association between FS status and current smoking}

OR $(95 \% \mathrm{Cl})$
Longitudinal fixed-effect model examining changes in FS and current smoking
Longitudinal tobit model examining FS status and smoking intensity

\begin{tabular}{|c|c|c|c|}
\hline \multicolumn{4}{|l|}{ Current FS } \\
\hline \multicolumn{4}{|l|}{ High FS } \\
\hline Marginal FS & $1.64^{\star \star *}$ (1.26 to 2.14$)$ & $1.49^{*}(1.04$ to 2.13$)$ & $1.16^{\star \star \star}$ (1.07 to 1.26$)$ \\
\hline Low FS & $1.90^{\star \star \star}$ ( 1.46 to 2.48$)$ & $1.77^{\star \star}$ (1.17 to 2.67$)$ & $1.22^{\star \star \star}(1.11$ to 1.33$)$ \\
\hline Very low FS & $2.44^{\star \star *}(1.84$ to 3.23$)$ & $1.62^{*}(1.01$ to 2.58$)$ & $1.17^{* *}(1.06$ to 1.30$)$ \\
\hline Observations & 2228 & 1766 & 11674 \\
\hline No of Unique IDs & 2228 & 351 & 2553 \\
\hline
\end{tabular}

${ }^{*} \mathrm{p}<0.05,{ }^{\star \star} \mathrm{p}<0.01,{ }^{* \star *} \mathrm{p}<0.001$.

0.53 to $0.81, \mathrm{p}<0.001)$. The association between food security status and current smoking was not modified by HIV status (not shown).

In the longitudinal individual fixed-effects model, becoming of marginal, low and very low food security status was associated with 1.49 (95\% CI: 1.04 to 2.13), 1.77 (95\% CI: 1.17 to 2.67$)$ and 1.62 (95\% CI: 1.01 to 2.58) times greater odds of becoming a current smoker, respectively, compared with becoming a non-smoker (table 2). In adjusted models, becoming marginal, low and very low food security were associated with 1.56 (95\% CI: 1.08 to 2.25 ), 1.88 (95\% CI: 1.23 to 2.87 ) and 1.66 (95\% CI: 1.02 to 2.81) times greater odds of becoming a current smoker, respectively, compared with becoming a non-smoker (table 3). In the adjusted model, none of the other time-varying variables were significantly associated with becoming a current smoker.

In the final model for smoking intensity, all study participants were included with non-smokers censored at zero. The unadjusted relative differences of intensity of smoking (cigarettes/day) were 1.16 (95\% CI: 1.07 to 1.26), 1.22 (95\% CI: 1.11 to 1.33) and 1.17 (95\% CI: 1.06 to 1.30$)$ times higher for women with marginal, low and very low food security status, respectively, compared with those with high food security (table 2 ). The adjusted relative differences of intensity of smoking were $1.17(95 \%$ CI: 1.07 to 1.27 ), 1.21 (95\% CI: 1.10 to 1.32 ), and 1.16 (95\% CI: 1.04 to 1.29) times higher for women with marginal, low and very low food security status, respectively, compared with those with high food security (table 3).

\section{DISCUSSION}

In this longitudinal study of WLWH and demographically similar women without HIV, food insecurity was associated with greater odds of being a current cigarette smoker, with higher odds of smoking as food insecurity severity worsened. Furthermore, any change in food security status was associated with a change in smoking status, and food insecurity was positively associated with smoking intensity. HIV status did not modify these associations, but HIV-seropositivity was associated with lower odds of being a current smoker and lower intensity of smoking compared with HIV-seronegative participants.

Our findings are consistent with literature on the association between food insecurity and smoking status among the general US population, ${ }^{28}$ and among women living with and at risk for HIV who experience housing instability. ${ }^{51}$ Our findings are not consistent with the literature among WLWH, who have a higher prevalence of smoking than their HIV-seronegative peers. ${ }^{52}$ While the prevalence of smoking in the cohort is relatively high, it is lower among WLWH (39\%) than demographically similar HIV-seronegative women $(49 \%, \mathrm{p}<0.001)$. Due to the nature of healthcare in the USA, WLWH may have access to more consistent healthcare compared with their demographically similar HIV-seronegative counterparts, allowing for more opportunities for smoking cessation referrals, which may in part explain the lower prevalence of smoking among WLWH in this study compared with the controls. In the WIHS, all women who reported smoking received information at each visit referring them to external smoking cessation programmes. Economically disadvantaged people and ethnic minorities typically have less access to smoking cessation treatment, ${ }^{5354}$ and women in general have less success in smoking cessation in the long-term than men. ${ }^{8}$ Given that this study was predominantly composed of these populations who are understudied among PLHIV in the USA, our study fills an important gap in the smoking and PLHIV literature.

Being food insecure was associated with 1.16-1.21 times higher (ie, 16\%-21\% higher) smoking intensity compared with being food secure, even after controlling for income. Food insecurity may drive higher smoking intensity through two mechanisms. First, food insecurity is a profound stressor that leads to poor mental health ${ }^{48}$ which in turn is associated with cigarette smoking. ${ }^{49} 50$ Second, tobacco acts as an appetite suppressant via the hypothalamus, ${ }^{55}{ }^{56}$ and food insecure individuals may smoke to cope with hunger. ${ }^{57} 58$ Given that measures of 
Table 3 Adjusted associations between food security (FS) and smoking outcomes

\begin{tabular}{|c|c|c|c|}
\hline & $\begin{array}{l}\text { Cross-sectional association } \\
\text { between FS status and } \\
\text { current smoking }\end{array}$ & $\begin{array}{l}\text { Longitudinal fixed-effect } \\
\text { model examining changes in } \\
\text { FS and current smoking }\end{array}$ & $\begin{array}{l}\text { Longitudinal Tobit model } \\
\text { examining FS status and } \\
\text { smoking intensity }\end{array}$ \\
\hline & AOR $(95 \% \mathrm{Cl})$ & AOR $(95 \% \mathrm{Cl})$ & Relative difference $(95 \% \mathrm{Cl})$ \\
\hline \multicolumn{4}{|l|}{ Current FS } \\
\hline High & Ref. & Ref. & Ref. \\
\hline Marginal FS & $1.52^{\star *}(1.14$ to 2.04$)$ & $1.56^{*}(1.08$ to 2.25$)$ & $1.17^{\star \star \star}(1.07$ to 1.27$)$ \\
\hline Low FS & $1.70^{\star \star \star}(1.28$ to 2.27$)$ & $1.88^{\star \star}(1.23$ to 2.87$)$ & $1.21^{\star \star \star}(1.10$ to 1.32$)$ \\
\hline Very low FS & $1.91^{* \star \star}(1.42$ to 2.59$)$ & $1.66^{\star}(1.02$ to 2.71$)$ & $1.16^{\star \star}$ (1.04 to 1.29$)$ \\
\hline HIV seropositivity (neg. ref) & $0.59^{\star \star \star}(0.48$ to 0.73$)$ & -- & $0.57^{\star \star \star}(0.46$ to 0.71$)$ \\
\hline Age at visit, years & 0.99 (0.98 to 1.00$)$ & 0.95 (0.83 to 1.08$)$ & 1.01 (1.00 to 1.02$)$ \\
\hline \multicolumn{4}{|l|}{ Race } \\
\hline Non-Hispanic white & Ref. & -- & Ref. \\
\hline Hispanic & $0.59^{*}(0.39$ to 0.90$)$ & -- & $0.54^{\star \star}(0.36$ to 0.80$)$ \\
\hline African American/black & $1.02(0.73$ to 1.44$)$ & -- & 0.99 (0.71 to 1.38$)$ \\
\hline Other & 0.77 (0.42 to 1.40$)$ & -- & 0.60 (0.33 to 1.07$)$ \\
\hline \multicolumn{4}{|l|}{ Income (US\$) } \\
\hline$<$ US\$12000 & Ref & Ref & Ref \\
\hline US\$12001-US\$24 000 & $0.78^{\star}(0.61$ to 0.98$)$ & 1.05 (0.73 to 1.52$)$ & $0.89^{* \star}(0.81$ to 0.97$)$ \\
\hline US\$24 001-US\$36000 & 0.84 (0.60 to 1.17$)$ & 1.05 (0.61 to 1.82$)$ & $0.82^{\star \star}(0.72$ to 0.93$)$ \\
\hline US\$36001-US\$75000 & $0.62^{*}(0.42$ to 0.93$)$ & $2.38^{*}$ (1.05 to 5.39$)$ & $0.80^{* *}(0.69$ to 0.94$)$ \\
\hline US\$75001 & $0.37^{\star *}(0.19$ to 0.71$)$ & $1.94(0.48$ to 7.80$)$ & $0.54^{\star \star \star}(0.42$ to 0.71$)$ \\
\hline Employed (unemployed ref) & $0.45^{\star \star *}(0.36$ to 0.57$)$ & 1.47 (0.94 to 2.30$)$ & $0.89^{* *}(0.81$ to 0.97$)$ \\
\hline \multicolumn{4}{|l|}{ Marital status } \\
\hline Partnered & Ref & Ref & Ref \\
\hline $\begin{array}{l}\text { Divorced/separated/ } \\
\text { widowed }\end{array}$ & 0.91 (0.70 to 1.17$)$ & 0.68 (0.40 to 1.14$)$ & 0.92 (0.82 to 1.03$)$ \\
\hline Never married & 0.94 (0.74 to 1.19$)$ & 0.98 (0.57 to 1.69$)$ & 1.00 (0.89 to 1.13$)$ \\
\hline Other & 1.07 (0.76 to 1.51$)$ & 0.68 (0.36 to 1.27$)$ & 0.92 (0.79 to 1.06$)$ \\
\hline \multicolumn{4}{|l|}{ Education (<high school ref) } \\
\hline zHigh school education & $0.54^{\star \star \star}(0.44$ to 0.66$)$ & - & $0.42^{\star \star \star}(0.34$ to 0.52$)$ \\
\hline \multicolumn{4}{|l|}{ Child dependents (none ref) } \\
\hline Yes & $0.66^{\star \star \star}(0.48$ to 0.73$)$ & 0.85 (0.56 to 1.29$)$ & 0.91 (0.83 to 1.00$)$ \\
\hline Observations & 2133 & 1700 & 11301 \\
\hline No of Unique IDs & 2133 & 344 & 2522 \\
\hline
\end{tabular}

${ }^{*} \mathrm{P}<0.05,{ }^{* *} \mathrm{p}<0.01,{ }^{* * *} \mathrm{p}<0.001$.

AOR, adjusted OR.

food insecurity and smoking intensity were obtained at the same study visit, and time between each visit (six months) was too long to assess directionality by staggering food insecurity and smoking intensity, we cannot determine which was driving the other. The consistency in linking food insecurity with smoking in low-income women living with and at risk for HIV here and in prior studies ${ }^{51}$ indicates the importance of addressing this issue.

Smoking intensity, however, did not have a dose response relationship with the severity of food insecurity. Two plausible mechanisms may explain this lack of a dose response relationship. First, being food insecure may coincide with volatility in financial resources, which in turn may affect one's ability to afford highly taxed cigarettes and subsequent smoking intensity but not affect smoking status. That is, people of low socioeconomic status are more likely to respond to increased cigarette taxation by reducing intensity of smoking but not by eliminating consumption of cigarettes compared with those of higher socioeconomic status. ${ }^{5960}$ Second, if foodinsecure individuals have access to programmes that alleviate but not eliminate food insecurity (allowing them to 
go from a previously very low food security status to low or moderate) via food banks, pantries or food stamps, then resources previously dedicated to food may be available for non-essential goods including cigarettes. Nevertheless, the relationship between food security and smoking intensity underscores the importance of integrating food security alleviation programmes with smoking cessation programming.

This study was unable to assess food insecurity nor changes in food security status as a predictor of smoking cessation success. Becoming food insecure (compared with maintaining a food secure status) is associated with lower odds of smoking cessation among smokers and with smoking initiation in non-smokers. ${ }^{28}$ Yet, we do not know if a change from being food insecure to food secure may prompt a reduction or cessation in cigarette smoking, presumably as the appetite-suppressing effects of cigarettes are no longer needed. These valuable data would shed light on the effectiveness of the integration of food insecurity alleviation in smoking cessation programming and could be used for policy development and scaled programming.

The study included a large, geographically diverse sample of WLWH and without HIV with similar demographic characteristics. A rich set of information was collected for each woman and models adjusted for appropriate control variables. Nevertheless, several potentially important individual characteristics that were not measured were smoking products and smoking behaviours, family history of smoking, previous cessation attempts, social support and participation in food insecurity alleviation programmes. Given that there were few differences in the longitudinal model (compared with the cross-sectional model) when we were able to control for individual variability, as well as the fixed effects model (which removed measured and unmeasured individual characteristics that do not change over time), the role of these potential confounders may be minimal. Collecting data on smoking intensity is notoriously difficult given variabilities in recalling smoking intensity. The survey questions assessed smoking intensity since the last visit six months earlier; long recall periods present opportunities for recall bias in self-reporting of health data. Likewise, food insecurity was assessed during that same recall period. Food security status may fluctuate on a monthly or weekly basis in households experiencing food or financial scarcity; a recall period of six months may not allow us to evaluate these periodic shifts. Further, we were unable to assess other types of common tobacco use, notably vaping and e-cigarettes, whose prevalence and public health impact are increasing greatly. The development of validated questions that can evaluate tobacco exposure from traditional (ie, cigarette, chewing tobacco, cigars) as well as new delivery mechanisms (ie, e-cigarettes, vaping) will facilitate a more accurate measurement of tobacco exposure. This potential misclassification in the exposure could bias results towards the null, whereby women who are food insecure and exclusive vape users were categorised as non-smokers, yet the paths from food insecurity and tobacco use and addiction potentially remain the same. Furthermore, although the prevalence of selfreported cigarette smoking was not low in the sample, there was little change in status over the assessed study visits, which may have limited estimation of the relationship between changes in smoking status and food security. Lastly, despite recent recruitment efforts to match the demographic profile of WLWH in the USA, ${ }^{43}$ WIHS women may not match the profile of those with incident HIV in the USA, notably regarding age, which has implications for the generalisability of this study.

In conclusion, food insecurity was associated with both being a smoker and smoking intensity in this sample of WLWH and without HIV. Smoking has a high attributable risk for preventable deaths in the USA and globally, and food insecurity may exacerbate this risk. Even on its own, food insecurity significantly increases persistent morbidity across multiple populations. ${ }^{6162}$ Food insecurity is modifiable and alleviating it should be considered in conjunction with smoking cessation programmes. Alleviating food insecurity through augmentation of resources while simultaneously reducing smoking, however, is challenging. For example, alleviating food insecurity in overweight women through resource augmentation has tended to exacerbate excess weight, ${ }^{63}$ but a recent randomised control trial has demonstrated that a programme that was carefully designed and implemented based on in-depth understanding of women's lives in Costa Rica ${ }^{64}$ was effective in simultaneously reducing food insecurity and excess body weight. ${ }^{65}$ Therefore, experimental or observational studies of programmes to alleviate food insecurity should collect data on recent tobacco initiators or quitters to provide valuable information on the contextual milieu that is related to smoking initiation, duration, intensity and cessation. With such information, researchers may be able to better identify those at risk for tobacco use initiation as well as design and enhance policies and programmes to simultaneously reduce food insecurity and promote smoking cessation.

\section{Author affiliations}

${ }^{1}$ Division of HIV, Infectious Diseases, and Global Medicine, University of California, San Francisco, California, USA

${ }^{2}$ Department of Health Promotion, Education, and Behavior, University of South Carolina System, Columbia, South Carolina, USA

${ }^{3}$ Community Health Sciences, School of Public Health, State University of New York Downstate Medical Center, Brooklyn, New York, USA

${ }^{4}$ Department of Epidemiology and Population Health, Albert Einstein College of Medicine, Bronx, New York, USA

${ }^{5}$ Family Medicine, Georgetown University Medical Center, Washington, District of Columbia, USA

${ }^{6}$ Medicine, John H Stroger Hospital of Cook County, Chicago, Illinois, USA ${ }^{7}$ School of Public Health, Johns Hopkins University, Baltimore, Maryland, USA ${ }^{8}$ School of Medicine, University of North Carolina at Chapel Hill, Chapel Hill, North Carolina, USA

${ }^{9}$ UNC Gillings School of Global Public Health, University of North Carolina at Chapel Hill, Chapel Hill, North Carolina, USA

${ }^{10}$ School of Medicine, Emory University, Atlanta, Georgia, USA

${ }^{11}$ Sociomedical Sciences, Columbia University Mailman School of Public Health, New York City, New York, USA 
${ }^{12}$ Department of Health Care Organization and Policy, School of Public Health, University of Alabama at Birmingham, Birmingham, Alabama, USA ${ }^{13}$ Department of Medicine, University of California, San Francisco, California, USA ${ }^{14}$ Department of Veteran Affairs Medical Center, San Francisco, California, USA ${ }^{15}$ Center for AIDS Prevention Studies, University of California, San Francisco, California, USA

Acknowledgements Publication made possible in part by support from the UCSF Open Access Publishing Fund.

Contributors Planning: SDW, PCT and EAF. Research and study design: LAS, SDW, EAF and PCT; data analysis: LAS and EAF; data interpretation: LAS, SDW, EAF, JH and EDR; data collection: LAS, KP, TEW, AA, DM, MC, ELW, AAA, IO, ELW, LM, JMT, PCT and SDW. All authors reviewed and provided feedback on intellectual content and approved the final version of the manuscript.

Funding This study was funded by a Women's Interagency HIV Study (WIHS) substudy grant from the National Institute of Mental Health, R01MH095683, a mentoring grant K24Al134326 (Weiser), and a scientist development grant K01DK107335 (Palar). Data in this manuscript were collected by the Womens Interagency HIV Study (WIHS), now the MACS/WIHS Combined Cohort Study (MWCCS). MWCCS (principal investigators): Atlanta CRS (Ighovwerha Ofotokun, Anandi Sheth and Gina Wingood), U01-HL146241; Baltimore CRS (Todd Brown and Joseph Margolick), U01-HL146201; Bronx CRS (Kathryn Anastos and Anjali Sharma), U01- HL146204; Brooklyn CRS (Deborah Gustafson and Tracey Wilson), U01-HL146202; Data Analysis and Coordination Centre (Gypsyamber D'Souza, Stephen Gange and Elizabeth Golub), U01-HL146193; Chicago-Cook County CRS (Mardge Cohen and Audrey French), U01-HL146245; Chicago- Northwestern CRS (Steven Wolinsky), U01-HL146240; Northern California CRS (Bradley Aouizerat, Jennifer Price and Phyllis Tien), U01-HL146242; Los Angeles CRS (Roger Detels and Matthew Mimiaga), U01-HL146333; Metropolitan Washington CRS (Seble Kassaye and Daniel Merenstein), U01- HL146205; Miami CRS (Maria Alcaide, Margaret Fischl and Deborah Jones), U01-HL146203; Pittsburgh CRS (Jeremy Martinson and Charles Rinaldo), U01-HL146208; UAB-MS CRS (Mirjam- Colette Kempf, Jodie Dionne-Odom, and Deborah Konkle-Parker), U01-HL146192; UNC CRS (Adaora Adimora), U01-HL146194. The MWCCS is funded primarily by the National Heart, Lung, and Blood Institute (NHLBI), with additional cofunding from the Eunice Kennedy Shriver National Institute Of Child Health and Human Development (NICHD), National Institute On Ageing (NIA), National Institute Of Dental and Craniofacial Research (NIDCR), National Institute Of Allergy And Infectious Diseases (NIAID), National Institute Of Neurological Disorders And Stroke (NINDS), National Institute Of Mental Health (NIMH), National Institute On Drug Abuse (NIDA), National Institute Of Nursing Research (NINR), National Cancer Institute (NCI), National Institute on Alcohol Abuse and Alcoholism (NIAAA), National Institute on Deafness and Other Communication Disorders (NIDCD), National Institute of Diabetes and Digestive and Kidney Diseases (NIDDK), National Institute on Minority Health and Health Disparities (NIMHD) and in coordination and alignment with the research priorities of the National Institutes of Health, Office of AIDS Research (OAR). MWCCS data collection is also supported by UL1- TR000004 (UCSF CTSA), P30-Al-050409 (Atlanta CFAR), P30-Al-050410 (UNC CFAR) and P30-Al- 027767 (UAB CFAR).

Disclaimer The contents of this publication are solely the responsibility of the authors and do not represent the official views of the National Institutes of Health (NIH).

\section{Competing interests None declared.}

Patient and public involvement Patients and/or the public were not involved in the design, or conduct, or reporting, or dissemination plans of this research.

\section{Patient consent for publication Not required.}

Ethics approval Institutional Review Boards at each of the following universities or institutions reviewed and approved the study procedures (per the MWCCS overall study director, approval numbers are not available): University of Mississippi Medical Center, University of North Carolina at Chapel Hill, University of Alabama at Birmingham, University of Miami, Emory University, Brooklyn WIHS site, SUNY Downstate Medical Center, Kings County Medical Center, Bronx WIHS site, Montefiore Medical Center, Beth Israel Medical Center, Mount Sinai School of Medicine, Chicago WIHS site, Cook County Health \& Hospitals System, Northwestern University, Rush University Medical Center, University of Illinois at Chicago, San Francisco WIHS site, University of California, San Francisco, Alameda Health System, Sutter Health, Santa Clara Valley Medical Center, San Mateo Medical Center, DC WIHS site, Georgetown University, Montgomery County Department of Health and Human Services, Inova, Howard University, Whitman-Walker Clinic
Provenance and peer review Not commissioned; externally peer reviewed.

Data availability statement Data may be obtained from a third party and are not publicly available. You may request access to the MACS or WIHS Public Use Data Set (MWCCS public use data set will be available in 2021 at https://airtable.com/ shrVDP51W5J2qcNeT), or you may submit a concept sheet in order to have access to the full MWCCS data set, which includes data not available in the PDS such as neurocognitive data, abuse data, healthy aging, etc. Having an approved concept sheet means you will receive assistance in understanding the MWCCS study and the complexity of the MWCCS data; linkage to a MWCCS liaison who can offer expertise in your area of study; support regarding study design, methodology and statistical analysis; and access to all summary files.

Open access This is an open access article distributed in accordance with the Creative Commons Attribution Non Commercial (CC BY-NC 4.0) license, which permits others to distribute, remix, adapt, build upon this work non-commercially, and license their derivative works on different terms, provided the original work is properly cited, appropriate credit is given, any changes made indicated, and the use is non-commercial. See: http://creativecommons.org/licenses/by-nc/4.0/.

ORCID iDs

Lila A Sheira http://orcid.org/0000-0002-1831-8506

Sheri D Weiser http://orcid.org/0000-0002-7807-4072

\section{REFERENCES}

1 Rentería E, Jha P, Forman D, et al. The impact of cigarette smoking on life expectancy between 1980 and 2010: a global perspective. Tob Control 2016;25:551-7.

2 World Health Organization. Global health risks: mortality and burden of disease attributable to selected major risks. Geneva: World Health Organization, 2009.

3 Courtney R. The health consequences of Smoking -50 years of progress: a report of the surgeon general, 2014 US department of health and human services. Atlanta, GA: Department of health and human services, centers for disease control and prevention, National center for chronic disease prevention and health promotion, office on smoking and health, 2015: 34. 694-5.

4 Centers for Disease Control and Prevention. Current Cigarette Smoking Among Adults in the United States,. Smoking \& Tobacco Use. Atlanta, GA: CDC, 2017.

5 Centers for Disease Control and Prevention. Burden of cigarette use in the U.S, 2019. Available: https://www.cdc.gov/tobacco/campaign/ tips/resources/data/cigarette-smoking-in-united-states.html

6 Garrett BE, Martell BN, Caraballo RS, et al. Socioeconomic differences in cigarette smoking among sociodemographic groups. Prev Chronic Dis 2019;16:E74.

7 Villarroel MA, Cha AE, Vahratian A. Electronic cigarette use among US adults, 2018, 2020.

8 Smith PH, Kasza KA, Hyland A, et al. Gender differences in medication use and cigarette smoking cessation: results from the International tobacco control four country survey. Nicotine Tob Res 2015;17:463-72.

9 Mikkelsen SS, Dalum P, Skov-Ettrup LS, et al. What characterises smokers who quit without using help? A study of users and nonusers of cessation support among successful ex-smokers. Tob Control 2015;24:556-61.

10 Perkins KA, Scott J. Sex differences in long-term smoking cessation rates due to nicotine patch. Nicotine Tob Res 2008;10:1245-50.

11 Mdodo R, Frazier EL, Dube SR, et al. Cigarette smoking prevalence among adults with HIV compared with the general adult population in the United States: cross-sectional surveys. Ann Intern Med 2015;162:335-44.

12 Conley LJ, Bush TJ, Buchbinder SP, et al. The association between cigarette smoking and selected HIV-related medical conditions. AIDS 1996;10:1121-6.

13 Diaz PT, King MA, Pacht ER, et al. Increased susceptibility to pulmonary emphysema among HIV-seropositive smokers. Ann Intern Med 2000;132:369-72.

14 Wewers MD, Diaz PT, Wewers ME, et al. Cigarette smoking in HIV infection induces a suppressive inflammatory environment in the lung. Am J Respir Crit Care Med 1998;158:1543-9.

15 Brown JL, Winhusen T, DiClemente RJ, et al. The association between cigarette smoking, virologic suppression, and CD4+ lymphocyte count in HIV-Infected Russian women. AIDS Care 2017;29:1102-6.

16 King D, Grasso C, Dant L, et al. Treatment outcomes associated with quitting cigarettes among sexual minority men living with HIV: 
antiretroviral adherence, engagement in care, and sustained HIV RNA suppression. AIDS Behav 2018;22:2868-76.

17 Clarke JR, Taylor IK, Fleming J, et al. The epidemiology of HIV-1 infection of the lung in AIDS patients. AIDS 1993;7:555-60.

18 Lifson AR, Neuhaus J, Arribas JR, et al. Smoking-Related health risks among persons with HIV in the strategies for management of antiretroviral therapy clinical trial. Am J Public Health 2010;100:1896-903.

19 Reddy KP, Kong CY, Hyle EP, et al. Lung cancer mortality associated with smoking and smoking cessation among people living with HIV in the United States. JAMA Intern Med 2017;177:1613-21.

20 Suy A, Martínez E, Coll O, et al. Increased risk of pre-eclampsia and fetal death in HIV-infected pregnant women receiving highly active antiretroviral therapy. AIDS 2006;20:59-66.

21 Aliyu $\mathrm{MH}$, Weldeselasse $\mathrm{H}$, August EM, et al. Cigarette smoking and fetal morbidity outcomes in a large cohort of HIV-infected mothers. Nicotine Tob Res 2013;15:177-84.

22 Calvet GA, Grinsztejn BGJ, Quintana MdeSB, et al. Predictors of early menopause in HIV-infected women: a prospective cohort study. Am J Obstet Gynecol 2015;212:765.e1-765.e13.

23 Rahmanian S, Wewers ME, Koletar S, et al. Cigarette smoking in the HIV-infected population. Proc Am Thorac Soc 2011;8:313-9.

24 Feldman JG, Minkoff H, Schneider MF, et al. Association of cigarette smoking with HIV prognosis among women in the HAART era: a report from the women's Interagency HIV study. Am J Public Health 2006;96:1060-5.

25 National Research Council. Food Insecurity and Hunger in the United States: An assessment of the Measure. Panel to Review the U.S. Department of Agriculture's Measurement of Food insecurity and Hunger. Washington, DC: The National Academics Press, 2006.

26 Campbell CC. Food insecurity: a nutritional outcome or a predictor variable? J Nutr 1991;121:408-15.

27 Farrelly MC, Shafer PR. Comparing trends between food insecurity and cigarette smoking among adults in the United States, 1998 to 2011. Am J Health Promot 2017;31:413-6.

$28 \mathrm{Kim}-$ Mozeleski JE, Seligman HK, Yen IH, et al. Changes in food insecurity and smoking status over time: analysis of the 2003 and 2015 panel study of income dynamics. Am J Health Promot 2019;33:698-707.

29 Coleman-Jensen AR, Gregory MP, CA Singh A. Household food security in the United States in 2017. U.S. Department of Agriculture, Economic Research Service, 2018.

30 Anema A, Vogenthaler N, Frongillo EA, et al. Food insecurity and HIV/ AIDS: current knowledge, gaps, and research priorities. Curr HIVI AIDS Rep 2009;6:224-31.

31 Langton A, Moxham R, Hirst S, et al. Food security in a sample of clients attending HIV clinics in New South Wales: a cross-sectional study. Nutr Diet 2018;75:468-73.

32 Weiser SD, Leiter K, Bangsberg DR, et al. Food insufficiency is associated with high-risk sexual behavior among women in Botswana and Swaziland. PLoS Med 2007;4:e260-97.

33 Normén L, Chan K, Braitstein P, et al. Food insecurity and hunger are prevalent among HIV-positive individuals in British Columbia, Canada. J Nutr 2005;135:820-5.

34 Tuthill EL, Sheira LA, Palar K, et al. Persistent food insecurity is associated with adverse mental health among women living with or at risk of HIV in the United States. J Nutr 2019;149:240-8.

35 Weiser S, Fernandes K, Anema A. Food insecurity as a barrier to antiretroviral therapy (art) adherence among HIV-infected individuals in British Columbia. 5th IAS conference on HIV pathogenesis. Cape Town, South Africa: Treatment and Prevention, 2009.

36 Whittle HJ, Sheira LA, Frongillo EA, et al. Longitudinal associations between food insecurity and substance use in a cohort of women with or at risk for HIV in the United States. Addiction 2019;114:127-36.

37 Weiser SD, Fernandes KA, Brandson EK, et al. The association between food insecurity and mortality among HIV-infected individuals on HAART. J Acquir Immune Defic Syndr 2009;52:342-9.

38 Anema A, Weiser SD, Fernandes KA, et al. High prevalence of food insecurity among HIV-infected individuals receiving HAART in a resource-rich setting. AIDS Care 2011;23:221-30.

39 Kim-Mozeleski JE, Tsoh JY, Ramirez-Forcier J, et al. Smoking predicts food insecurity severity among persons living with HIV. AIDS Behav 2018;22:2861-7.

40 Kapulsky L, Tang AM, Forrester JE. Food insecurity, depression, and social support in HIV-infected Hispanic individuals. J Immigr Minor Health 2015;17:408-13.
41 Barkan SE, Melnick SL, Preston-Martin S, et al. The women's Interagency HIV study. WIHS collaborative Study Group. Epidemiology 1998;9:117-25.

42 Bacon MC, von Wyl V, Alden C, et al. The women's Interagency HIV study: an observational cohort brings clinical sciences to the bench. Clin Diagn Lab Immunol 2005;12:1013-9.

43 Adimora AA, Ramirez C, Benning L, et al. Cohort profile: the women's Interagency HIV study (WIHS). Int J Epidemiol 2018;47:393-4.

44 Frongillo EA. Validation of measures of food insecurity and hunger. $J$ Nutr 1999;129:506S-9.

45 Radimer KL, Olson CM, Greene JC, et al. Understanding hunger and developing indicators to assess it in women and children. $J$ Nutr Educ 1992;24:36S-44.

46 Hamelin A-M, Beaudry M, Habicht J-P. Characterization of household food insecurity in Québec: food and feelings. Soc Sci Med 2002;54:119-32.

47 Bickel G, Nord M, Price C. Guide to measuring household food security, revised. Alexandria, VA: Food and Nutrition Service, US. Department of Agriculture, 2000.

48 Whittle HJ, Sheira LA, Wolfe WR, et al. Food insecurity is associated with anxiety, stress, and symptoms of posttraumatic stress disorder in a cohort of women with or at risk of HIV in the United States. $J$ Nutr 2019;149:1393-403.

49 Taylor G, McNeill A, Girling A, et al. Change in mental health after smoking cessation: systematic review and meta-analysis. BMJ 2014;348:g1151.

50 Prochaska JJ. Smoking and mental illness - breaking the link. $N$ Engl J Med Overseas Ed 2011;365:196-8.

51 Kim JE, Flentje A, Tsoh JY, et al. Cigarette smoking among women who are homeless or unstably housed: examining the role of food insecurity. J Urban Health 2017;94:514-24.

52 Weinberger AH, Smith PH, Funk AP, et al. Sex differences in tobacco use among persons living with HIV/AIDS: a systematic review and meta-analysis. J Acquir Immune Defic Syndr 2017;74:439-53.

53 Browning KK, Ferketich AK, Salsberry PJ, et al. Socioeconomic disparity in provider-delivered assistance to quit smoking. Nicotine Tob Res 2008;10:55-61.

54 Houston TK, Scarinci IC, Person SD, et al. Patient smoking cessation advice by health care providers: the role of ethnicity, socioeconomic status, and health. Am J Public Health 2005;95:1056-61.

55 Miyata G, Meguid MM, Fetissov SO, et al. Nicotine's effect on hypothalamic neurotransmitters and appetite regulation. Surgery 1999;126:255-63.

56 Frankish HM, Dryden S, Wang Q, et al. Nicotine administration reduces neuropeptide $Y$ and neuropeptide $Y$ mRNA concentrations in the rat hypothalamus: NPY may mediate nicotine's effects on energy balance. Brain Res 1995;694:139-46.

57 Cheskin LJ, Hess JM, Henningfield J, et al. Calorie restriction increases cigarette use in adult smokers. Psychopharmacology 2005; 179:430-6.

58 Leeman RF, O'Malley SS, White MA, et al. Nicotine and food deprivation decrease the ability to resist smoking. Psychopharmacology 2010;212:25-32.

59 Bader P, Boisclair D, Ferrence R. Effects of tobacco taxation and pricing on smoking behavior in high risk populations: a knowledge synthesis. Int J Environ Res Public Health 2011;8:4118-39.

60 Farrelly MC, Bray JW, Pechacek T, et al. Response by adults to increases in cigarette prices by sociodemographic characteristics. South Econ J 2001;68:156-65.

61 Wells JC, Sawaya AL, Wibaek R, et al. The double burden of malnutrition: aetiological pathways and consequences for health. Lancet 2020;395:75-88.

62 Cox J, Hamelin A-M, McLinden T, et al. Food insecurity in HIVhepatitis $C$ virus co-infected individuals in Canada: the importance of co-morbidities. AIDS Behav 2017;21:792-802.

63 Leroy JL, Gadsden P, González de Cossío T, et al. Cash and in-kind transfers lead to excess weight gain in a population of women with a high prevalence of overweight in rural Mexico. J Nutr 2013;143:378-83.

64 Martínez-Jaikel T, Frongillo EA. Primary role of discouragement in coexistence of food insecurity and excess weight in Costa Rican women. J Hunger Environ Nutr 2016;11:210-26.

65 Martínez-Jaikel T, Frongillo EA, Blake CE, et al. Reducing both food insecurity and excess body weight in Costa Rican women: a cluster randomized trial. Am J Prev Med 2020;58:736-47. 